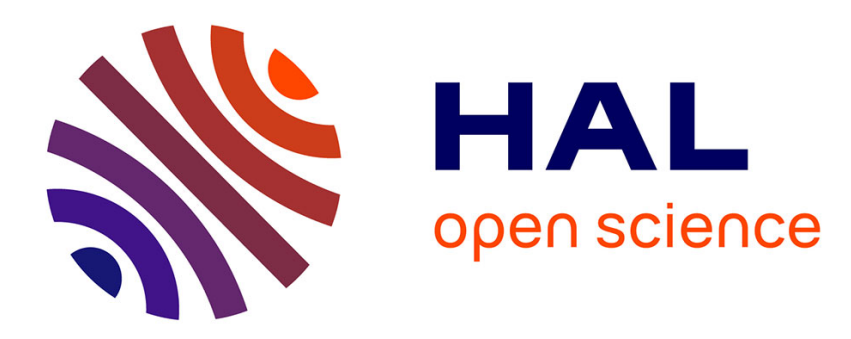

\title{
Chemical vapor deposition of hafnium carbide and hafnium nitride
}

\author{
G. Emig, G. Schoch, O. Wormer
}

\section{To cite this version:}

G. Emig, G. Schoch, O. Wormer. Chemical vapor deposition of hafnium carbide and hafnium nitride. Journal de Physique IV Proceedings, 1993, 03 (C3), pp.C3-535-C3-540. 10.1051/jp4:1993374 jpa00251431

\section{HAL Id: jpa-00251431 https://hal.science/jpa-00251431}

Submitted on 1 Jan 1993

HAL is a multi-disciplinary open access archive for the deposit and dissemination of scientific research documents, whether they are published or not. The documents may come from teaching and research institutions in France or abroad, or from public or private research centers.
L'archive ouverte pluridisciplinaire HAL, est destinée au dépôt et à la diffusion de documents scientifiques de niveau recherche, publiés ou non, émanant des établissements d'enseignement et de recherche français ou étrangers, des laboratoires publics ou privés. 


\title{
Chemical vapor deposition of hafnium carbide and hafnium nitride
}

\author{
G. EMIG, G. SCHOCH* and O. WORMER*
}

Institut für Technische Chemie 1, Universität Erlangen-Nürnberg, Egerlandstrasse 3, 8520 Erlangen, Germany

* Institut für Chemische Technik der Universität Karlsruhe Kaiserstr. 12, 7500 Karlsruhe 1, Germany

\section{Abstract}

The paper describes alternative high- temperature coatings for carbon fiber reinforced carbon (CFC) and carbon fiber reinforced silicon carbide $(\mathrm{C} / \mathrm{SiC})$ comparing $\mathrm{CVD}$ of hafnium carbide and hafnium nitride. Hafnium carbide and hafnium nitride layers were obtained in a thermally- stimulated CVD reactor by reaction of hafnium tetrachloride, methan and addition of hydrogen. Thermodynamic modeling of the reactions

$$
\begin{aligned}
& \mathrm{HfCl}_{4}+\mathrm{H}_{2}+\mathrm{CH}_{4} \rightarrow \mathrm{HfC}, \mathrm{HfCl}_{4-x}, \mathrm{C}, \mathrm{HCl} \\
& \mathrm{HfCl}_{4}+\mathrm{H}_{2}+\mathrm{N}_{2} \rightarrow \mathrm{HfN}, \mathrm{HfCl}_{4-\times}, \mathrm{HCl}
\end{aligned}
$$

shows the possibility of depositing a nearly carbon- free hafnium carbide layer, but HfN should be deposited at lower temperatures without any solid byproduct. These theoretical calculations could be proved experimentally in a thermally activated CVD process.

\section{Introduction}

CFC and $\mathrm{C} / \mathrm{SiC}$ provide outstanding opportunities for future high temperature applications. Due to their instability in air at higher temperatures, they need protective coatings. Up to now, silicon dioxide is a widely used coating, despite its low melting point. Silicon carbide provides a far better protection, but reacts with its oxidation product silicon dioxide yielding the volatile monoxide. This reaction starts at approximately $1400^{\circ} \mathrm{C}$ and thus destroys the protective layer. Hafnium carbide and hafnium nitride exhibit extremely high melting points of $3887^{\circ} \mathrm{C}^{1}$ and $3310^{\circ} \mathrm{C}^{2}$, and no volatile monoxides are known. Thermogravimetric determination of the mass change of pure $\mathrm{HfC}$ and $\mathrm{HfN}$ powders $(\approx 300$ mesh) obtained from Johnson Mathey, Alfa Products, in oxygen $(75 \mathrm{ccm} / \mathrm{min}$.) at a heating rate of $10 \mathrm{~K} / \mathrm{min}$ show a about $200^{\circ} \mathrm{C}$ higher oxidation resistance for $\mathrm{HfN}$ than $\mathrm{HFC}$, Fig. 1. Compared with $\mathrm{SiC}$, the oxidation resistance of both compounds appears poor. Nevertheless, HfC is believed to

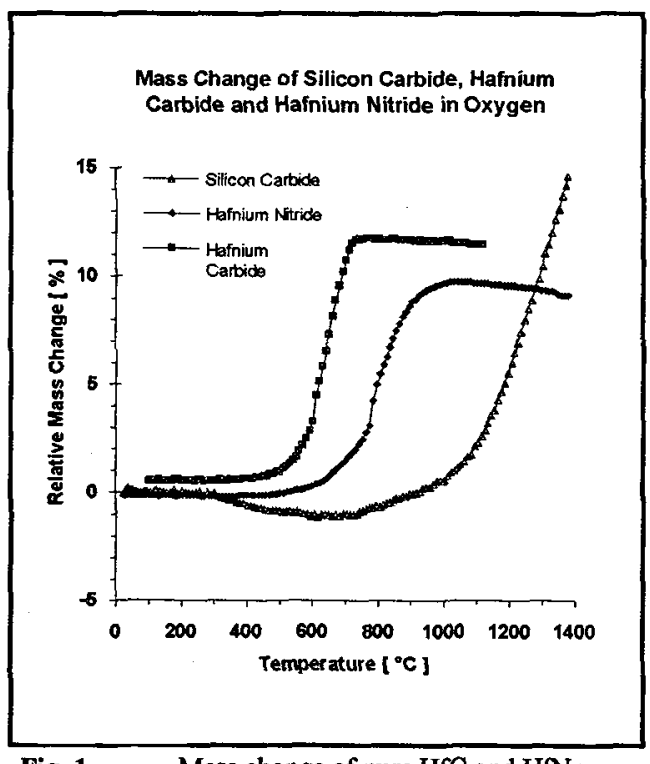

Fig. 1
Mass change of pure $\mathrm{HfC}$ and $\mathrm{HfN}$ powders compared to $\mathrm{SiC}$ 
be an interesting candidate as a part of high-temperature protective coatings for CFC and $\mathrm{C} / \mathrm{SiC}$ - Composites 3 due to the refractory, thermally insulating dioxide and the formation of an oxide interlayer $\mathrm{HfO}_{2-\mathrm{x}} \mathrm{C}_{\mathrm{Y}}{ }^{4}$.

\section{Thermodynamic Calculations}

Thermodynamic calculations based on minimization of the Gibbs free energies were performed with a PC program 5 using the well-known Solgasmix- algorithms and a thermodynamic database ${ }^{6}$ as well as calculated ${ }^{7}$ and experimentally determined values ${ }^{8}$. Although hafnium monohalide is a well-known solid ${ }^{9}$, experimental results neglect its existence. This compound, different $\mathrm{HfC}_{1-\mathrm{x}}$ species as well as a possible $\mathrm{Hf}_{2} \mathrm{~N}$ phase were not taken into account.

\section{Calculation results in the System $\mathrm{HFCl}_{4}-\mathrm{CH}_{4}-\mathrm{H}_{2}$}

Starting with equivalent concentrations of $1 \mathrm{~mol} \mathrm{HfCl}_{4}$ and $\mathrm{CH}_{4}$ in the temperature range from 800 to $1200^{\circ} \mathrm{C}$, a total pressure of 50 mbar and a surplus of hydrogen from 10 to $100 \mathrm{~mol}$, calculations showed that $\mathrm{HfCl}_{3}$ and car-

\begin{tabular}{|c|c|c|c|c|c|c|c|c|c|}
\hline & \multicolumn{3}{|c|}{$800^{\circ} \mathrm{C}$} & \multicolumn{3}{|c|}{$1000^{\circ} \mathrm{C}$} & \multicolumn{3}{|c|}{$1200^{\circ} \mathrm{C}$} \\
\hline & \multicolumn{3}{|c|}{$\mathrm{H}_{2}: \mathrm{CH}_{4}$ - ratio } & \multicolumn{3}{|c|}{$\mathrm{H}_{2}: \mathrm{CH}_{4}$-ratio } & \multicolumn{3}{|c|}{$\mathrm{H}_{2}: \mathrm{CH}_{4}$ - ratio } \\
\hline & 1:100 & $1: 50$ & 1:10 & $1: 100$ & $1: 50$ & 1:10 & 1:100 & $1: 50$ & $1: 10$ \\
\hline $\mathbf{H}_{2}$ & 100,8 & 51,08 & 11,56 & 100,5 & 50,76 & 11,24 & 100,4 & 50,54 & 11,01 \\
\hline $\mathrm{CH}_{4}$ & 0,12 & 0,07 & 0,02 & 0,02 & 0,01 & $<0,01$ & $<0,01$ & $<0,01$ & $<0,01$ \\
\hline HCl & 1,99 & 1,54 & 0,79 & 2,87 & 2,43 & 1,5 & 3,29 & 2,92 & 1,98 \\
\hline $\mathrm{HfCl}_{3}$ & 0,37 & 0,37 & 0,29 & 0,34 & 0,45 & 0,6 & 0,23 & 0,35 & 0,62 \\
\hline $\mathrm{HfCl}_{4}$ & 0,22 & 0,34 & 0,58 & 0,02 & 0,05 & 0,18 & $<0,01$ & 0,01 & 0,04 \\
\hline C & 0,48 & 0,63 & 0,86 & 0,35 & 0,49 & 0,77 & 0,23 & 0,36 & 0,66 \\
\hline HfC & 0,4 & 0,29 & 0,12 & 0,63 & 0,49 & 0,23 & 0,76 & 0,64 & 0,34 \\
\hline
\end{tabular}
bon are always present. The $\mathrm{HfCl}_{2-}$ content, which is not shown in the table, is neglectable small $(<0,01 \mathrm{~mol})$. Values are summarized in table 1 for a total pressure of 50 mbar.

Varying the $\mathrm{HfCl}_{4}$ to $\mathrm{CH}_{4}$ ratio at different temperatures, a total pressure of $50 \mathrm{mbar}$ and a $\mathrm{HfCl}_{4}$ to hydrogen ratio of 1:100 leads to the conclusion that the deposition of carbon can be minimized by a $\mathrm{HfCl}_{4}$ surplus ratio between 2,5 and 4,5. This effect is even more important at higher temperatures as shown in figure 2.

Influence of the Hafniumtetrachlorid : Methan-Ratio

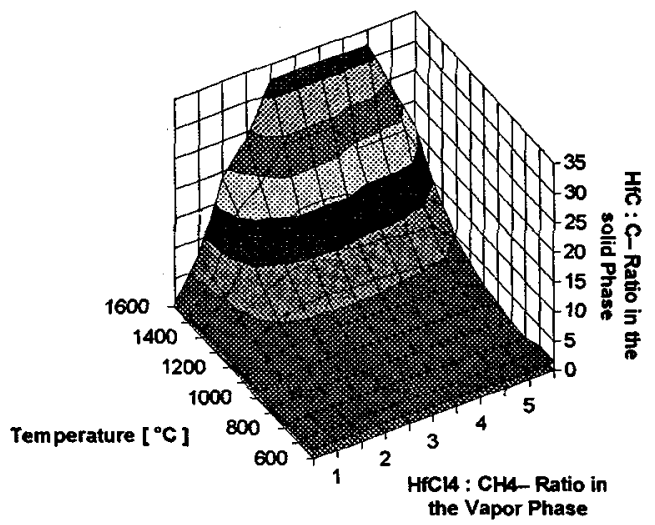

Figure $2 \quad \mathrm{HfC}: \mathrm{C}$ - ratio as a function of the $\mathrm{HfCl}_{4}: \mathrm{CH}_{4}$-ratio in the vapor phase
It is mentioned 10 that higher deposition rates should be obtained by means of in- situ chlorinating of metallic hafnium with a surplus of hydrogen, thus leading to the formation of hafnium subchlorides. Although it is true that the reaction of methan with hafnium subchlorides is less endothermic than with $\mathrm{HfCl}_{4}{ }^{11}$, their sublimation temperatures are quite higher 12 . The exothermic 
chlorination of hafnium thus leads to the readily volatile, white $\mathrm{HfCl}_{4}$, to distinguish from the intense colored hafnium subchlorides ${ }^{13}$.

\section{Calculation results in the System $\mathrm{HFCl}_{4}-\mathrm{N}_{2}-\mathrm{H}_{2}$}



Figure 3 Calculation results in the system $\mathrm{HfCl}_{4}-\mathrm{N}_{2}-\mathrm{H}_{2}$. used values :

Influence of temperature:

Influence of pressure:

Influence of hydrogen surplus

Influence of nitrogen surplus
$\mathrm{HfCl}_{4}: \mathrm{N}_{2}: \mathrm{H}_{2}$ according $1: 100: 100,50 \mathrm{mbar}$

$\mathrm{HfCl}_{4}: \mathrm{N}_{2}: \mathrm{H}_{2}$ according $1: 100: 100,1000^{\circ} \mathrm{C}$

$\mathrm{HfCl}_{4}: \mathrm{N}_{2}$ according $1: 100,1000^{\circ} \mathrm{C}, 50 \mathrm{mbar}$

$\mathrm{HfCl}_{4}: \mathrm{H}_{2}$ according $1: 100,1000^{\circ} \mathrm{C}, 50$ mbar 
In $\mathrm{HfC}-\mathrm{CVD}$, rising $\mathrm{CH}_{4}$ - content lead to an increase of carbon deposition, whereas in $\mathrm{HAN}-\mathrm{CVD}$ a surplus of nitrogen increases deposition of HfN. The reaction temperature reaches a shallow optimum and dependence of pressure is quite neglectable. According to these findings shown in figure 3, optimum deposition conditions are about $1000^{\circ} \mathrm{C}$ with high nitrogen and hydrogen ratio towards $\mathrm{HfCl}_{4}$, depending from experimental setup.

\section{Experimental Section}



Abb. 4
Apparatus
CVD layers were obtained in a thermally- stimulated CVD- equipment as shown in figure 4. As substrates, platelets made of glasslike (i. e. nonporous) carbon and quartz were used. Gases were obtained from Messer- Grießheim, Germany $\left(\mathrm{H}_{2}\right.$ 5.0, $\mathrm{CH}_{4} 2.5$, $\left.\mathrm{N}_{2} 5.0\right)$ and purified further with Oxysorb cartridges $\left(\mathrm{Cr}^{2+}-\right.$ complex and molecular sieve) from Messer- Grießheim). Gas mixtures werc obtained by metering desired quantities

of each gas through calibrated mass flow meters (Bronkhorst $\mathrm{Hi}-\mathrm{Tec}$, The Netherlands). $\mathrm{HfCl}_{4}$ from Johnson Mathew, GmbH Alfa Products was handled in an argon box and filled into the sublimator. The partial pressure of $\mathrm{HfCl}_{4}$ was taken as the vapor pressure at the temperature of the sublimator ${ }^{14}$.

\section{Chemical Vapor Deposition of HfC and SNMS Analysis of HfC Layers}

$\mathrm{HfC}$ - layers with a typical thickness of about $2,5 \mu \mathrm{m}$ were prepared on platelets made of $\mathrm{SiO}_{2}$ and glassy carbon. Depth- resolved distributions of the elements $\mathrm{C}, \mathrm{O}, \mathrm{Si}, \mathrm{Hf}$ and as a possible contaminant chlorine were measured with Plasma- SNMS (Secondary Neutral Mass Spectrometry). Analysis was performed with the INA3- system (SPECS, Berlin, Germany). The sample surface is sputtered by ions of a low pressure Argon rf plasma with kinetic energies of $400 \mathrm{eV}$ and a current density of $0.7 \mathrm{~mA} / \mathrm{cm}^{2}$. A cooling system kept the temperature of the sample below $10^{\circ} \mathrm{C}$. The emitted neutral surface atoms are ionized by plasma electrons, mass separated in a quadruple filter, and further detected by a secondary electron multiplier 15 .

The atomic SNMS signals of the relevant elements have been recorded versus sputter time. With known erosion rates, these time profiles were converted into depth profiles. To prevent charging, the samples are covered by a tantalum grid (100 mesh, transmission $60 \%$ ). Conversion of atomic intensities into relative concentrations was performed using detection factors obtained from measurements of pure $\mathrm{HfC}, \mathrm{HfO}_{2}$ and $\mathrm{HfN}$. The powdered pure compounds were pressed into indium foil as carrier. An erosion rate of $1 \mathrm{~nm} / \mathrm{s}$ was calculated taking into account the thickness of the HfC layers of about $2 \mu \mathrm{m}$, obtained from SEM images of fracture edges, and the sputter time necessary to reach the interface between $\mathrm{HfC}$ and the substrate.

Due to several experimental problems with the highly hygroscopic $\mathrm{HfCl}_{4}$, the determination of kinetic parameters of $\mathrm{HfCl}_{4}-\mathrm{CVD}$ must still be continued. Up to now, experimental results confirm the above described thermodynamic calculations. However, SNMS analysis of deposited layers ${ }^{16}$ clearly showed oxygen contamination in some layers, thus leading to deposition of hafnium dioxide. 
As shown in figure 5, the ratio of carbon to hafnium concentration roughly agrees with the stoichiometry of HfC.

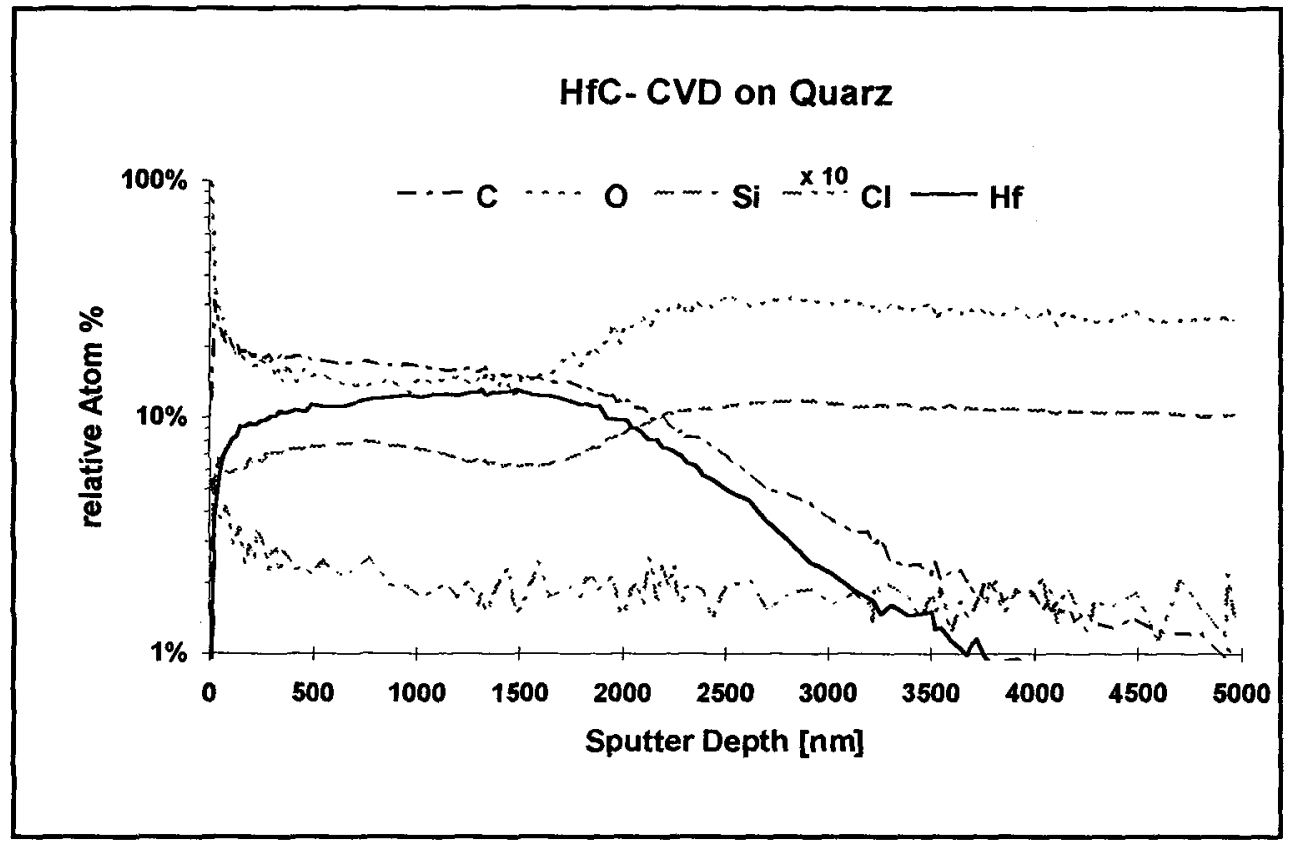

Figure 5 Element distribution obtained by SNMS- analysis of a sample prepared at $1060^{\circ} \mathrm{C}, \mathrm{HfCl}_{4}: \mathrm{CH}_{4}$ : $\mathrm{H}_{2}$ according to $0,6: 1: 11$ and 50 mbar

The concentration of carbon was determined to be at least $30 \%$ more than hafinium for a depth $>1 \mu \mathrm{m}$. Near to the surface, the carbon concentration exceeds the $\mathrm{HfC}$ - stoichiometry more than in deeper regions. The extremely high $\mathrm{C} / \mathrm{Hf}$ intensity ratios at the very surface $(10 \mathrm{~nm})$ are due to sputter relaxation phenomena. The interface region extends into both phases by $0.3 \mu \mathrm{m}$, probably due to interdiffusion. The depth resolution of the instrument under the given experimental conditions was checked to be much lower, namely $10 \mathrm{~nm}$. Silicon and oxygen signals in the low depth region should not be explained as an incoherent $\mathrm{HfC}$ layer but as uncovered borders of the $\mathrm{SiO}_{2}$ substrate. A nearly constant contamination of chlorine over the whole investigated area was found.

\section{Chemical Vapor Deposition of HfN}

Hafnium nitride could be deposited in the thermodynamically predicted region. Measurable deposition started at $700^{\circ} \mathrm{C}$. In the temperature region from 700 to $900^{\circ} \mathrm{C}$, a golden layer like the similar TiN was found. At higher temperatures, the layers grow more grayish. Deposition rates as a function of inverse temperature are shown in figure 6.

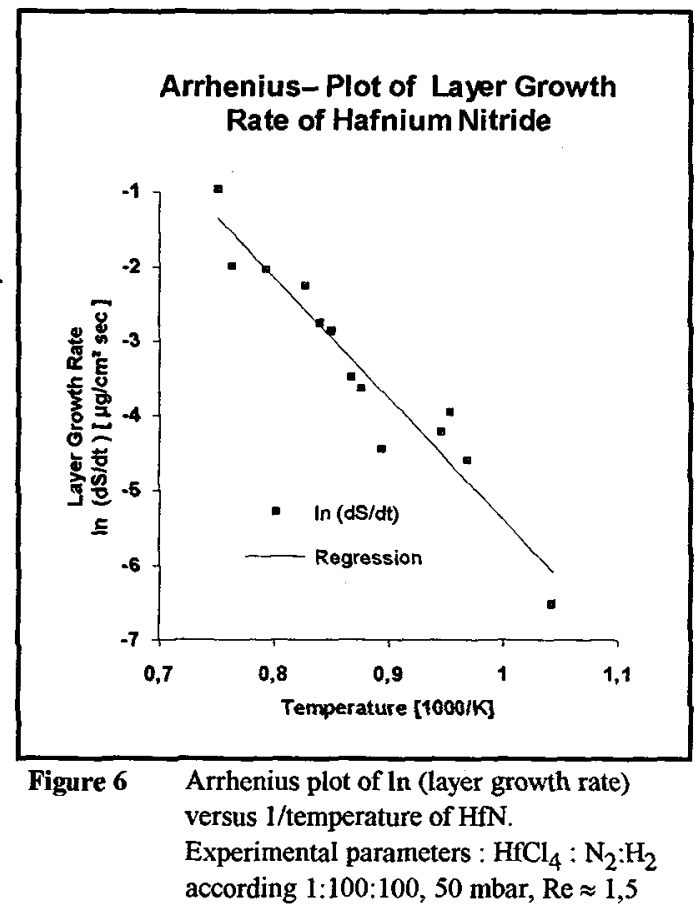




\section{Summary}

Thermodynamic calculations are useful in predicting optimal temperature and concentrations for CVD of HfC and HAN. SNMS as a new analysis tool in CVD was successfully employed in analyzing deposited thin film layers of hafnium carbide. The important carbon content in the HfC layers as well as chlorine contamination could be obtained as a function of the layer depth. HfN, a possible oxidation protective coating as an alternative to HfC, could be deposited according to the shown thermodynamic calculations at lower temperatures.

\section{Acknowledgments}

The authors wish to thank the DFG Deutsche Forschungsgemeinschaft for their financial support and Prof. Dr. Bärnighausen and Mr. Kuhn, Institut fuer Anorganische Chemie II, Universitaet Karlsruhe, for their valuable support in handling the highly hygroscopic hafnium tetrachloride.

\section{References}

[1] Agte, C.; Alterthum, H., Zeitschrift für Technische Physik 11182 (1930)

[2] Ruff, O., $15^{\text {th }}$ Congr. Chim. ind., Bruxelles 68 (1935); Chim. Ind. 3546 (1936)

[3] Bavarian, Behzad; Arrieta, Victor, $35^{\text {th }}$ International SAMPE Symposium 351348 (1990)

[4] Bargeron, B. C.; Benson, R. C.; Jette, N. A.; Phillips, T. E.J. Am. Ceram. Soc. 76 1040-1046 (1993)

[5] Barin, I.; Erikson, G.; Gauert, .; Zeitler, M.;Wittig, B.; Schmidt, W.; Goldamer, Wolfgang, VCH, Münster, 1993

[6] Barin, I. Knacke, O., Springer Verlag, Berlin 1977

[7] Tsirel'nikov, V.I., Russ. J. Phys. Chem 47913 (1973)

[8] Dittmer, G.; Niemann, U., Philips Journal of Research 42151987

[9] Strauss, Arthur W.; Corbett, John D., Inorganic Chemistry 91373 (1970)

[10] Lackey, W.J.; Hanigofsky, J. A.; Freeman, Garth B., Journal of the American Ceramical Society 73 1593 (1990)

[11] Kaplan, Richard B., Proc. Int. Conf. Chemical Vapor Deposition, $3^{\text {rd }} 176-183$ (1972)

[12] Izmailovich, S.I.; Troyanov, S.I; Tsirel'nikov, V.I.; Kommissarova, L.N. Russian J. of Inorg. Chem. 14 452 (1969)

[13] Corbett, John D.; Struss, Arthur W., Inorganic Chemistry 9 (1970) 1373

[14] Palko, A.A.; Ryon, A.D.; Kuhn, D.W, J. of phys. Chem. 62319 (1958)

[15] Fichtner, M., Goschnick, J., Schmidt, U. C., Schweiker, A., Ache, H. F.J. Vac. Sci. Technol. A 10(2) 362 , 1992

[16] Ache, H.F.; Goschnick, J; Sommer, M.; Emig, G.; Schoch, G.; Wormer, O., E-MRS Spring Meeting Straßbourg 1993, to be published in Thin Solid Films 